\section{Questión}

Periodismo / Comunicación

ISSN 1669-6581

La radio: vacuna sonora contra la Covid-19 en Cuba

Zenaida Costales Pérez, Lys Máriam Alfonso Bergantiño

Question/Cuestión, Vol. 2, N66, Agosto 2020

ISSNe 1669-6581

https://perio.unlp.edu.ar/ojs/index.php/question/index

IICom-FPyCS-UNLP

DOI: https//doi.org/10.24215/16696581e471

\title{
La radio: vacuna sonora contra la covid-19 en Cuba
}

\section{The radio: sound vaccine against covid-19 in Cuba}

Zenaida Costales Pérez

Facultad de Comunicación, Universidad de La Habana, Cuba

costaleszenaida@gmail.com

https://orcid.org/0000-0001-9561-5144

Lys Máriam Alfonso Bergantiño

Facultad de Comunicación, Universidad de La Habana, Cuba

lamariam1996@gmail.com

https://orcid.org/0000-0002-9639-6788 


\section{Resumen}

El presente trabajo pretende reconocer el papel de la radio ante la actual crisis sanitaria que enfrenta el mundo, provocada por la Covid-19. Se centra especialmente en Cuba, cuyo sistema nacional de radio se ha reorganizado para extender sus ondas sonoras a una mayor audiencia, a partir del cambio de programación, los encadenamientos nacionales y las nuevas rutinas productivas. El relato de las radios comunitarias ha encontrado espacio oportuno en las emisoras nacionales, resaltando las historias de los cubanos en el enfrentamiento a la enfermedad. La presencia de las emisoras cubanas en Internet con audio real y el acceso de los cubanos a las nuevas tecnologías ha permitido la participación activa de un mayor número de personas y, en consecuencia, el aumento de la audiencia. La radio cubana resurge renovada ante esta nueva coyuntura sanitaria.

\section{Palabras clave}

Cuba; radio; pandemia; COVID-19.

\section{Abstract}

This work aims to recognize the role of radio in the face of the current health crisis facing the world, caused by Covid-19. It focuses especially on Cuba, whose national radio system has been reorganized to extend its sound waves to a wider audience, starting with the change in programming, national chains and new production routines. The story of the community radio stations has found opportune space in the national radio stations, highlighting the stories of the Cubans in the confrontation with the disease. The presence of Cuban radio stations on the Internet with real audio and the access of Cubans to new 
technologies has allowed the active participation of a greater number of people and, consequently, the increase in audience. Cuban radio resurfaces renewed before this new health situation.

\section{Key Words}

Cuba; radio; pandemic; Covid-19.

\section{Introducción}

Los sonidos de una ciudad son comunes en nuestras vidas, habitamos en ellos, formamos parte de sus códigos. El claxon de los carros, la música en los autobuses, el pregón de los vendedores, el repique de las campanas de la Iglesia, los pasos apresurados de la sociedad en constante movimiento, son algunas de las sonoridades diarias en la vida del más simple habitante. Su presencia se pasa por alto muchas veces y hasta resulta abrumadora, pero, ¿y su ausencia?, ¿seguiríamos siendo los mismos sin los sonidos?

La Habana es una ciudad ruidosa, el calor de su gente, la algarabía, los ritmos cubanos por todas partes. Sin embargo, el confinamiento, como medida preventiva ante la actual pandemia de la Covid-19, cambió los sonidos de la capital y de toda Cuba. El aislamiento obligó al país al silencio.

Desde que inició la crisis de salud, la posibilidad de estar en contacto con los sonidos a los que estamos acostumbrados ha desaparecido. El encierro tiene su propia sonoridad. Los que quedan en casa, teletrabajando o cumpliendo con la cuarentena, ahora prestan más atención a las sirenas de las ambulancias, las noticias en los medios, los aplausos al personal de la salud, las rutinas de los vecinos, los sonidos del hogar, las voces, la música que evoca nostalgias y esperanzas. 
Aunque lo cotidiano de la vida no permita que los apreciemos con especial atención, los sonidos distinguen, forman parte de la identidad individual y colectiva de la humanidad. Un sonido puede trasladarnos hacia una época, una vivencia e incluso un olor, con solo escucharlo. Es capaz de despertar emociones, sensaciones, pulsar la imaginación e influir en los estados de ánimo.

José Ignacio López Vigil, en su libro Manual urgente para radialistas apasionados, resume los principales descubrimientos del hombre en la búsqueda constante de los sonidos. Primero el telégrafo, invento del norteamericano Samuel Morse para comunicar, mediante mensajes codificados, una parte y otra del país. Este sería el cimiento para que Graham Bell, años más tarde, concibiera al teléfono como el instrumento capaz de trasladar la voz y los sonidos de forma inmediata, sin importar la distancia. "La voz humana iba y venía sin necesidad de ningún alfabeto para descifrarla. Si viajaba la voz, podía viajar la música. Y cualquier ruido. El sonido había roto para siempre con la esclavitud de la distancia" (López, 1997, p.9).

El fonógrafo de Alva Edison, la telegrafía sin hilos de Marconi, la primera radiotransmisión de sonidos de Fessenden y la capacidad de Lee de Forest para transformar estas modulaciones en señales eléctricas, fueron sentando las bases para que, finalmente, surgiera la radio, perpetuando el sonido que ArmandBalsebre (1994) describe como "todo ruido elaborado o clasificado en una cadena significante" (p. 20). Esos "ruidos", además de viajar en el espacio, serían eternos.

Es así como, desde el siglo XX, la radio acompaña, informa, entretiene y crea un vínculo entrañable con sus oyentes. El contacto entre ambas partes va más allá de la mera transmisión de mensajes y convierte a los radioescuchas, al 
mismo tiempo, en cómplices, escépticos, críticos, admiradores y detractores de los contenidos radiofónicos.

La radio se inserta y participa en ese espacio de interpretación y producción de sentidos para cumplir con la responsabilidad social que le fue concedida como dueña del aire. De esta forma, la conexión que se establece entre la audiencia $y$ los realizadores refleja la medida en que las ondas hertzianas han evolucionado para convertirse en uno de los medios de comunicación trascendentales, cuya misión es concertar todas las piezas que conforman el denominado lenguaje radiofónico, definido como:

“(...) el conjunto de formas sonoras y no sonoras representadas por los sistemas expresivos de la palabra, la música, los efectos sonoros y el silencio, cuya significación viene determinada por el conjunto de los recursos técnicoexpresivos de la reproducción sonora y el conjunto de factores que caracterizan el proceso de percepción sonora e imaginativo-visual de los radioyentes" (Balsebre, 1994, p.27).

El lenguaje radiofónico "(...) puede crear ambientes, escenarios, decorados, vestuarios, climas, sentimientos, ilusiones, alegrías, miedos, siempre y cuando esté bien estructurado, adecuadamente utilizado, oportunamente emitido" (Romo, 1997, p.6).

\section{El lenguaje sanador de la radio}

Es indudable la necesidad creciente del hombre de comunicarse y encontrar nuevas formas para ello. Transmitir sonoridades que identifican y perpetuar lo sonoro en el tiempo: la música, las palabras, los efectos, ha sido resultado de los esfuerzos humanos por dejar una huella en la historia y ahí ha estado la radio para ello, como aliada en diferentes procesos históricos y socioculturales. 
A través de sus ondas se conectaron fronteras en tiempos de guerra, se alivió la incertidumbre de familias separadas, se movilizaron los pueblos en pos de una causa justa, y hoy, ante la nueva pandemia, como en cada periodo adverso, la radio resurge renovada.

"Un medio viejo que en agosto cumplirá 100 años reafirma que no resucitó: siempre estuvo vivo, como servicio esencial tildado de antiguo. La radio en tiempos de coronavirus es vacuna" (Zucchi, 2020). Anima, cura, consuela, acompaña. En tiempos en que la soledad y el distanciamiento de los otros es la mejor forma de mantenerse a salvo, la radio entra a los hogares para llevar su magia sanadora y hacer sentir que no estamos solos.

La credibilidad de la radio y su capacidad para generar empatía con los oyentes son algunas de las razones que han permitido que durante estos meses de pandemia las escuchas lograran un aumento significativo. Un estudio realizado en España a raíz de la crisis sanitaria por la COVID-19 demuestra lo siguiente:

En cuanto al tratamiento de situaciones de crisis y en concreto, del coronavirus, la radio es el medio que para los encuestados mejor está tratando el tema $(42 \%)$, seguido de la televisión $(35 \%)$, internet $(12 \%)$, prensa $(8 \%)$, redes sociales $(2 \%)$ y revistas (1\%). (Rodero, 2020, p. 6)

La audiencia, ahora en casa, experimenta un acercamiento al medio radial a través de diferentes vías. La radio tradicional se complementa con las nuevas tecnologías para llegar por medio de dispositivos móviles y redes sociales y establecer una retroalimentación con sus escuchas, ahora también internautas. Los adultos mayores, la principal audiencia de la radio, reafirma su fidelidad al medio, pero también se incorporan nuevos oyentes atraídos por la necesidad creciente de buscar información veraz y compañía. 
Fernando Vásquez (1998) profesor de la Pontificia Universidad Javeriana de Colombia define, en su opinión, la esencia de este medio de comunicación: La radio reúne, aglutina. La radio se asemeja al antiguo fuego tutelar, a la taza de café o al vaso de cerveza (...) La radio es una ausencia que se hace presencia. Una voz que encarna cuando la escuchamos. Un aire que nos refresca o nos recuerda el vaivén, el movimiento de lo vivo. La radio como la voz, y a diferencia de la letra, siempre es una forma viva, sensitiva. Una forma para el sentimiento. (p. 21)

¿Cuántos no hemos imaginado a locutores, actores, realizadores radiales, de una forma totalmente diferente a como suelen ser en realidad? La palabra, acompañada de otros elementos radiofónicos como la música, los efectos o el silencio, es un estímulo poderoso capaz de generar diferentes reacciones en los que se hallan del otro lado del éter. Es aquí donde entra en juego la voz, cuya cadencia, fuerza, timbre, ritmo, deben ser convincentes, creativos y dialogar con el radioyente como si estuviese justo en frente, contagiando confianza, intimidad y naturalidad. Ese es el encanto de este medio: colocar todos los sentidos en función de las emociones, no solo el auditivo.

Un medio que, al decir de la Doctora en Ciencias de la Comunicación y profesora de la Facultad de Comunicación de la Universidad de La Habana, Ana Teresa Badía (2010) "es el más extendido del mundo y las encuestas lo confirman como el más creíble. En América Latina es el medio de mayor cobertura y penetración social (...)" (p. 6). 


\section{Covid-19: la radio cubana más cerca de la audiencia}

Precisamente, esa sensación de acompañamiento, complicidad y cercanía de la radio, hace que en situaciones de crisis esté presente. En Cuba, durante desastres naturales que con frecuencia azotan la isla, como ciclones y huracanes, la radio ha sido la única vía para mantenerse informado. $Y$ ahora, en medio de la situación generada por la Covid-19, se reinventa y amplía sus ondas para participar junto a la ciudadanía en el enfrentamiento a esa enfermedad.

Aunque no esté concluido aún un estudio de recepción actualizado sobre los niveles de audiencia de la radio cubana en este periodo de pandemia, los datos ofrecidos hasta el momento por el Sistema Nacional de la Radio cubana, los resultados de los estudios de audiencia referida del Centro de Investigaciones Sociales del Instituto Cubano de Radio y Televisión (CIS), las entrevistas a sus directivos y las opiniones de algunos de los corresponsales en distintas emisoras de la geografía nacional, permiten establecer una visión en torno al papel de la radio en Cuba durante la Covid- 19.

El Sistema Nacional de la Radio Cubana está integrado por 100 emisoras, de ellas una internacional, seis nacionales, 19 provinciales y 74 municipales. Del total de ellas, 95 transmiten audio real por Internet.

Ante la coyuntura de la pandemia, este sistema se reorganiza. Se decide incrementar las horas de transmisión y establecer cambios en la programación. Esta última, concebida de forma más abierta y flexible, al priorizar un formato histórico: la radio revista, que permite establecer un diálogo ameno y creativo con los oyentes, así como insertar secciones de noticias, música, mensajes de bien público, entrevistas, entre otras propuestas informativas y de entretenimiento. 
El director general de la Radio Cubana, Onelio Castillo Corderí, detalla los tres ejes de acción principales durante esta etapa:

Primero: seleccionar las emisoras principales que llevarían el liderazgo en la información: Radio Rebelde, Radio Reloj y Radio Progreso como emisoras nacionales y el gran núcleo de la radio territorial, compuesto por 93 emisoras entre provinciales y municipales. Segundo: proyectar la transformación de los diseños de programación con un incremento notable de la programación en vivo. Tercero: ponderar el concepto de la radio cubana como un potente sistema de comunicación capaz de articular con unidad todas sus estrategias de trabajo, lo cual implicó llevar adelante los encadenamientos nacionales de las 100 emisoras del país para propiciar la mayor cantidad posible de información sobre el enfrenamiento a la pandemia. (Castillo, 2020)

A partir de estas estrategias, la radio de Cuba contribuiría a elevar la percepción de riesgo, informar acerca de las medidas para la prevención del virus y, a su vez, transmitir confianza y optimismo a la población. Las emisoras de la isla unirían esfuerzos a partir del encadenamiento para que la información oportuna llegara a una audiencia mayor. "Una de las decisiones más inteligentes que puede tomar un medio para reunir a esa audiencia dispersa es apelar a un sentido de comunidad, de colaboración. Generar información con impacto social" (Salaverría, 2020).

Radio Rebelde, la emisora insigne de la radio cubana, fundada por Ernesto Che Guevara durante la etapa final de la lucha contra la tiranía de Fulgencio Batista, asume su liderazgo en el actual combate contra la pandemia. Logra integrar a 96 emisoras del país en la radio revista especial Todos por Cuba, con el objetivo de brindar información sobre las acciones aprobadas por el 
gobierno para la prevención y control de la Covid-19 y las medidas que se adoptan desde la atención primaria de salud y los principales sectores. Todos por Cuba presenta dos emisiones al día en cadena nacional y permite la interconexión entre las diferentes emisoras de Cuba, haciendo que las historias particulares de cada región trasciendan la frontera de local para convertirse en el relato país.

Esta radio revista nacional transmite diariamente a las 9:00 AM la Conferencia de Prensa del Doctor Francisco Durán, director del Instituto de Epidemiología del Ministerio de Salud Pública, siendo esta emisión, propia de la etapa de pandemia, la que goza de mayor audiencia en la radio nacional.

La experiencia del Sistema de la Radio Cubana en el escenario de la Covid-19 ha otorgado una nueva dimensión a la producción comunicativa en la isla, puesto que no solamente logró unir simultáneamente la mayoría de las emisoras nacionales, sino que permitió develar la grandeza en la vida cotidiana de los cubanos.

"Llevamos más de 2.1 millones de trabajos y de acciones comunicativas realizadas a lo largo y ancho del país con un crecimiento creativo de los modos de hacer, con transformaciones numerosísimas en cada una de las emisoras cubanas durante los últimos tres meses" (Castillo, 2020).

Más del 70 por ciento del tiempo al aire del sistema de la Radio Cubana ha tenido un cambio totalmente renovador en esta contingencia epidemiológica. "Estamos hablando prácticamente de mil horas diarias, que cambiaron toda su composición y empezaron a mostrarle a nuestro pueblo una propuesta comunicativa diferente" (Ibídem). 
El mayor peso en los tributos ha sido de las radios municipales. Con el cambio en la programación, el relato local se extendió al territorio nacional e internacional, este último, a partir del audio real en Internet. Las historias de cada región del país lograron insertarse en el diarismo de la radio nacional, visibilidad que no era habitual antes del contexto de la pandemia, pues en su mayoría los contenidos de las radios municipales y provinciales corresponden a la audiencia de una comunidad determinada.

Las historias de vida de médicos, científicos, periodistas, campesinos, las voces del pueblo en general, llegadas desde diferentes parajes del país, se han insertado en la parrilla de programación de la radio nacional, retomando la narración oral, las vivencias, las tradiciones. La radio cubana abre los micrófonos para ponderar, en primera persona, el relato de quienes resisten y enfrentan la enfermedad.

Retomar como fuentes de las visualidades y lo digital a las tradiciones orales, los modos culturales de narración, las músicas y las experiencias radiales. ¿Para qué? Para hacer de lo sonoro una marca de la comunicación audiovisual y digital. ¡Lo sonoro es marca visual! (Rincón y Forero, 2008, p. 209)

De las mil cuatrocientas treinta y ocho horas diarias, un total de 88,3 por ciento pertenece a emisoras provinciales y municipales. De ahí el extraordinario peso que tiene la radio local en el acontecer informativo y en el vínculo constante con sus audiencias. Ha resultado de gran impacto la participación de los radioyentes a través de las vías creadas para ello: llamadas telefónicas, mensajería móvil, redes sociales, para aportar con su debate a temas sensibles como la gestión de la pandemia y la producción de alimentos.

En la localidad más occidental del país, la experiencia de Radio Guamá, emisora de la provincia de Pinar del Río, contribuyó a informar a comunidades 
que por razones preventivas permanecieron en régimen de confinamiento. Es el caso de las zonas de Camilo Cienfuegos, en Consolación del Sur, y La Ceiba, en Guane, donde también se crearon radio bases para transmitir urgentes mensajes de bien público y aprovechar el encadenamiento con la radio provincial a determinadas horas. Este vínculo permitió a la población permanecer informada en medio de una urgencia de salud que demanda altos contenidos informativos.

"Hoy en tiempos de emergencia sanitaria la radio privilegia la información por encima de la música y el deporte $y$, sin lugar a dudas, la conferencia de prensa del doctor Francisco Durán a las nueve de la mañana tiene total audiencia", reconoce la periodista Alina Cabrera Domínguez, corresponsal de Radio Rebelde en Pinar del Río, refiriéndose al parte diario del Ministerio de Salud Pública Cubana sobre la actualización de la situación epidemiológica en el país.

En la zona central de Cuba, la emisora provincial CMHW, conocida como "La Reina Radial del Centro", cuenta con una larga tradición de audiencia en sus más de ocho décadas de transmisiones. Ante el nuevo escenario, aumenta la agilidad en la realización de productos radiales para asegurar la información oportuna. Sus ondas se trasladan hasta las comunidades más alejadas, los centros de aislamiento y conecta a los ciudadanos con el gobierno, el Consejo de Defensa Provincial y los organismos decisores en esta etapa.

$\mathrm{Ni}$ siquiera las condiciones de aislamiento pudieron con la fuerza de penetración de la radio. Una sala de cuidados intensivos, un médico con un celular explicando la evolución de un paciente y su misión altruista, un paciente en un centro de aislamiento agradeciendo la atención del personal médico. Eso 
fue auténticamente genial. (M. Cadalso, comunicación personal, 5 de mayo de 2020)

En el oriente de Cuba, durante el enfrentamiento a la Covid-19, la experiencia resultó similar al resto del país. Para las comunidades de esta zona de la geografía cubana fue esencial mantener el contacto con el acontecer nacional, pero las transmisiones de emisoras locales derivaron en las más escuchadas en estos territorios, según recientes sondeos realizados por el CISen las 15 provincias del país, incluida la capital, con una muestra de más 3000 sujetos encuestados.

Ha sido evidente en estos meses que existe un mayor interés por parte de quienes ocupan cargos en la dirección de los territorios en conectar e interactuar con la población en medio de la situación de emergencia.

Aroldo García, corresponsal hace más de treinta años de la planta matriz de la red de emisoras de Cuba confiesa: "nunca antes vi ese interés marcado de organismos e instituciones que se han percatado que nuestra radio llega a la mayoría y que los públicos están ávidos de información y recurren a ella para conocer lo que pasa". (A. García, comunicación personal, 10 de mayo de 2020).

\section{Las nuevas tecnologías en función del medio radial}

Gracias a la convergencia mediática, la radio logra insertar también sus contenidos en diferentes soportes comunicativos y aprovecha los rasgos de la comunicación en red, que distinguen al periodismo en internet: hipertextualidad, multimedialidad e interactividad, para que la audiencia participe de este proceso. Con internet, los recursos sonoros se articulan en un discurso más amplio y no se pierden en la fugacidad del éter. Al perpetuar los sonidos, una 
de las principales limitaciones del medio radial queda solventada. Se torna necesario retomar el concepto de ciberradio, definido por el catedrático español Mariano Cebrián Herreros (2008) como:

Un universo nuevo con sus tiempos y espacios correspondientes, diferentes al mundo real y al del mundo radiofónico tradicional. Es una radio sin límites de espacios. Se superan las divisiones tradicionales de la radio local, regional, autonómica, nacional e internacional. Ahora todo es global. (p. 26-27)

Es posible acceder a los contenidos que proponen diferentes emisoras, las cuales ofrecen ahora a sus oyentes la opción de escuchar la programación en vivo de forma online o descargarlos para la escucha diferida, indagar en sus sitios web e interactuar a través de las redes sociales.

En función de la programación especial y de la información están las herramientas que ofrecen las redes sociales que como nunca antes, en el caso de Cuba, han probado de manera muy visible la capacidad de adaptación de la radio. Correos electrónicos, foros debates, conciertos online, video conferencias, entrevistas vía WhatsApp, podcasts, páginas web más parecidas a sus emisoras en antena.

La red de emisoras cubanas cuenta con un sistema de 70 sitios web que se ha mantenido activo, actualizando sus contenidos durante todas estas jornadas de enfrentamiento a la pandemia. "Han crecido sensiblemente los niveles de búsqueda de información a través de los sitios web, a partir de los perfiles institucionales de las emisoras en redes sociales, no solamente por el público nacional sino más allá de las fronteras cubanas". (Castillo, 2020)

La dinamización de la participación de las audiencias y el empleo de las nuevas tecnologías, como elemento distintivo de la radio moderna, ha permitido que los escuchas puedan tomar parte activamente en el enfrentamiento a la 
enfermedad. Según estadísticas del Portal de la Radio Cubana, en los cinco primeros meses del año 2020, la Radio Cubana ha tenido el impacto de medio millón de ciberescuchas en su página de audio real, lo que constituye un récord en comparación con igual periodo del año anterior. Solo en el mes de mayo, el número de visitas a la página supera las 130944 al espacio reservado para el audio en tiempo real del Portal de la Radio Cubana en Internet. (M.S. Campanioni, comunicación personal, 3 de junio de 2020).

Ha existido un incremento tanto de los accesos a los materiales en audio, insertados en el canal de audio y video del Instituto Cubano de Radio y Televisión y los canales en inglés y español de la Radio Cubana, como los canales de otras emisoras, con mayor influencia en Radio Rebelde, Radio Habana Cuba, la emisora provincial CMHW, y las municipales Radio Siboney, Radio Bayamo y Radio Grito de Baire.

En el caso de las emisoras nacionales, las más escuchadas online en el mes de mayo son:

1- Radio Rebelde: Con un total de 12981 y 4:03 minutos de promedio

2- Radio Progreso: Con un total de 9,798 y 3:57 minutos de promedio

3- Radio Taíno: Con un total de 7081 y 4:51 minutos de promedio

4- Radio Reloj: Con un total de 6167 y 4:43 minutos de promedio

5- Radio Enciclopedia: Con un total de 5669 y 4:23 de promedio De las emisoras provinciales las de mayor ranking de escucha:

1- Radio Sancti Spíritus: Con un total de 5510 y 4:23 de promedio

2- Radio Angulo (Holguín) Con un total de 5071 y 3:34 de promedio

3- Radio Cadena Agramonte (Camagüey) Con 3553 y 3:49 de promedio

4- CMHW (Villa Clara) Con 4074 y 4:16 minutos de promedio

5- Radio CMKC (Santiago de Cuba) Con 3322 y 5:53 de tiempo promedio 
En el caso de las emisoras municipales:

1- Radio Libertad (Las Tunas) Con 4577 y 4:39 de tiempo promedio

2- Radio Granma (Manzanillo) Con 3371 y 3:48 de tiempo promedio

3- Radio Banes (Holguín) Con 2766 y 6:17 de tiempo promedio

4- Radio Mayarí (Con 2058 y 4:02 de tiempo promedio

5- Radio COCO (La Habana) Con 1605 y 1:37 de tiempo promedio

\section{Potenciar la creación radial para la comunicación}

Información, música, entretenimiento, en ese orden, están en la preferencia de los radioyentes. La radio cubana intenta privilegiarlos en todos sus espacios, realzando el rol de las radio revistas. Especialmente en las actuales circunstancias de aislamiento social, la creación musical se ha estimulado. Piezas de autores cubanos como Valientes, del dúo Buena Fe, Depende de ti, de Arnaldo Rodríguez y Quiero verte otra vez, de Alexander Abreu, destacan entre las más logradas en lo que a música popular se refiere.

Además, desde diversas latitudes creadores musicales han hecho presencia en las redes sociales con sus conciertos online. En varias naciones se han escogido piezas musicales como emblema de la lucha contra la pandemia. Hermosos ejemplos son: Cómo la cigarra, de María Elena Walsh interpretada para el ciberespacio por varios cantantes argentinos, y Resistiré, original del dúo Los Dinámicos (Manolo y Ramón), montada con similar propósito por artistas españoles.

La puesta al aire de los conciertos desde casa de artistas cubanos e internacionales dinamiza los diseños de programación. Las emisoras Radio Progreso y Radio Rebelde son difusores principales de los sucesos culturales. La músicadesempeña un papel preponderante como balance en la intensidad 
de los contenidos informativos y se convierte tanto en un medio de distensión, como en un mensaje cultural y simbólico.

Es posible apreciar, durante esta etapa, un crecimiento creativo reflejado también en la construcción de mensajes de bien público. Con la existencia de una notable tradición en este género en Cuba, no sorprende que en tiempos de contingencia sanitaria sean uno de los productos radiales más empleados.

En la realización de estos materiales confluyen textos más atractivos, dramatizaciones, efectos sonoros y otros recursos como la locución, que permiten interpretar y transmitir una intención determinada. Todo lo anterior debe ser expresado en pocos segundos de duración y construido con la inmediatez inherente al medio.

La certera presencia de los mensajes cortos ha mantenido a la audiencia al tanto de todo lo concerniente a las medidas para prevenir los efectos de la pandemia. Las cuñas promocionales han divulgado, también, las presentaciones online de los artistas nacionales y foráneos, así como la realización de importantes eventos en las redes sociales. A las voces de locutores profesionales se han sumado varias figuras públicas y de manera muy especial la familia cubana que, desde casa, a través de la línea telefónica, ha formado parte de esos mensajes. La vocación orientadora y de facilitación social de la radio cubana se ha enriquecido en estos meses con la presencia de psicólogos, especialistas en nutrición, técnicos en cultura física, entre otros expertos, iniciativa que también ha contribuido a que la audiencia de las emisoras cubanas en este periodo se incremente (Castillo, 2020).

Muchas de estas nuevas medidas adoptadas a raíz de la pandemia han propiciado que la radio cubana cumpla un rol relevante tanto en la información, el entretenimiento y la orientación social. No en vano han sido calificadas por 
gran parte de la audiencia como una experiencia valiosa que debe permanecer después de la Covid-19.

Entre los elementos recogidos por las encuestas del CIS sobre las solicitudes de la audiencia para el periodo post pandemia, destacan las principales observaciones:

- Mantener la presencia sistemática de psicólogos, epidemiólogos y otros especialistas.

- La presencia de las autoridades del Partido Comunista de Cuba y el Gobierno.

- Continuar la programación en vivo con espacios dinámicos, de más duración, que contengan boletines de noticias, entradas de periodistas en directo, mayor participación, trabajos informativos y buena música.

- Conservar los encadenamientos, el tributo a las emisoras nacionales y la permanencia del espacio Todos por Cuba.

\section{Conclusiones}

El Sistema de la Radio Cubana cuenta con protocolos de respuesta comunicacional ante condiciones de desastres naturales para cada una de las fases. Pero la crisis sanitaria generada por la pandemia a nivel global requirió nuevos procederes y cambió las rutinas productivas. Sobre la marcha, se elaboró la estrategia mediática y la radio con sus recursos sonoros y la tecnología logró posicionarse en la preferencia de los oyentes, demostrando que juega un papel fundamental en situaciones de emergencia.

Los realizadores y periodistas de la radio, desde sus casas, llevaron la información oportuna a la audiencia, matizada con ruidos ambientes e historias de resistencia personal. Radio Rebelde encadenó a la mayoría de las emisoras del país para garantizar la información, Radio Reloj informó minuto a minuto, 
Radio Progreso retomó antiguas radionovelas y dramatizados, Radio Enciclopedia transmitió sosiego con la música instrumental, Radio Taíno y CMBF se encargaron de las manifestaciones artísticas. Las emisoras provinciales y municipales cumplieron el propósito de llevar el relato de sus comunidades al discurso de país.

Sin dudas, junto a los médicos, héroes indiscutibles de esta contienda, la comunicación social destaca en la cobertura mediática a la pandemia. La radio cubana, en especial, reivindica su espacio en la preferencia durante situaciones de crisis, desastres o emergencias. Reafirmó en estos meses de \#QuédateEnCasa su vocación de servicio, su capacidad para orientar, informar y entretener pero, sobre todo, su don para acompañar, transmitir confianza y llegar a la intimidad de los oyentes en momentos de soledad, ansiedad y consternación. Demostró que tiene una audiencia fiel y que es posible incorporar nuevos oyentes a partir del empleo eficaz de las nuevas tecnologías. La radio cubana, entre las más veteranas de la región latinoamericana, llega a su aniversario 98 de fundada reafirmando su compromiso de permanecer al lado de los oyentes, especialmente, en los escenarios más difíciles.

\section{Bibliografía}

- Badía, A. T. (2010). Bases teórico-metodológicas para el análisis del discurso radiofónico como fuente de reproducción ideológica. La Voz de América: un estudio de caso (tesis doctoral). Facultad de Comunicación, La Habana.

- Balsebre, A. (1994). El lenguaje radiofónico. Madrid, España: Cátedra. 
- Cebrián, M. (2008). La radio en Internet: De la ciberradio a las redes sociales y a la radio móvil. Buenos Aires: Ed. La Crujía.

- Castillo, O. (mayo de 2020). Cuba contra la COVID-19 / Entrevistado por Randy Alonso.

Mesa

Redonda.https://www.youtube.com/watch?v=0uBVDqFP-NQ

- López, J. I. (1997). Manual Urgente para Radialistas Apasionados. 1ra Ed. Quito, Ecuador: AMARAC.

- Los Tiempos (3 de mayo de 2020). Salaverría habla sobre el impacto de la pandemia en el ejercicio del periodismo. [Archivo de video]. Recuperado dehttps://www.youtube.com/watch?v=2D2Q4uwwGgU

- Rodero, E. (2020). La radio: el medio que mejor se comporta en las crisis. Hábitos de escucha, consumo y percepción de los oyentes de radio durante el confinamiento por el Covid-19. El profesional de la información, 29, (3),e290306. https://doi.org/10.3145/epi.2020.may.06

- Romo, C. (abril de 1997). El lenguaje seductor de la radio. [Conferencia]. Primer Congreso Internacional de la Lengua Española. Zacatecas, México.

- Vásquez, F. (1998). Amigos invisibles. Signo y Pensamiento, 18 (33), 21 26.

Recuperado dehttps://revistas.javeriana.edu.co/index.php/signoypensamiento/article/v iew/3010 
- Zucchi, M. (20 de marzo de 2020). La radio en tiempos de coronavirus: cumple 100 años y se vuelve más fuerte. Clarín. Recuperado de https://www.clarin.com/espectaculos/radio-tiempos-coronavirus-cumple100-anos-vuelve-fuerte $0 \mathrm{M} 9 \mathrm{GrIRNnJ.html}$ 